\title{
La interdisciplinariedad científico-técnica en el ámbito actual de la traductología/translémica, la lingüística aplicada y el discurso artístico
}

\author{
ANTONio Ñíguez BeRnAL \\ Universidad Complutense de Madrid \\ antonioniguez@yahoo.es
}

Recibido: 25 de junio de 2010

Aceptado: 15 de enero de 2011

\section{RESUMEN}

El objetivo de este artículo es profundizar en la valiosa contribución de la investigación interdisciplinar internacional en el campo de los estudios de traducción, lingüística, ciencias sociales y discurso artístico. Además, teniendo en cuenta que el arte difiere de la vida en cuanto a su propia existencia temporal, las obras maestras -incluyendo aquí la exactitud y precisión en el campo de la traductología/translémica y la interpretación-, pueden siempre aliviar el tedio vital y las pesadas tribulaciones de nuestra existencia cotidiana, librándonos de riesgos monetarios inútiles, pesadillas y depresiones nerviosas.

Uno de los propósitos fundamentales de cualquier artista, traductor o intérprete de lenguas, es crear buenas novelas, cuadros excelentes y, ¿por qué no?, traducciones o interpretaciones fieles al original. Desde un enfoque estadístico, un compositor puede ser tan reconocido como un cantante de ópera o un músico de jazz y, del mismo modo, un poeta, un traductor o un intérprete eficaz de Naciones Unidas, ser tan apreciados como un famoso bailarín del Bolshoi, si aceptamos que todos ellos complacen a lectores y espectadores exigentes. Por lo tanto, podemos concluir que a diversas formas del mundo de la cultura y del conocimiento, cabe reconocerles el mismo valor interdisciplinar y prestigio internacional.

Palabras clave: interdisciplinariedad, traductología/translémica, lingüística aplicada, discurso artístico.

Scientific and technical interdisciplinary within the present scope of traductology/translemics, applied linguistics and artistic discourse 


\begin{abstract}
The intention of this article is to examine thoroughly the valuable contribution of international interdisciplinary research in the fields of translation studies, linguistics, social sciences and artistic discourse. Moreover, bearing in mind that art differs from life in its own permanence, masterpieces -including here the accuracy in the field of traductology/translemics and interpreting-, can always compensate for tedium vitae and the heavy burdens of our daily existence, sparing us the trouble of useless money risks, nightmares and nervous breakdowns.

One of the main purposes of any artist, translator or language interpreter, is the creation of exciting novels, fabulous paintings or, why not, excellent accurate translations. Statistically speaking, a music composer is no more truly an artist than an opera singer or a jazz player; and, equally, a poet, an efficient translator or an interpreter in United Nations may not be less appreciated than a famous Bolshoi ballet dancer, if we consider that they all please demanding readers and theatrical audiences. Therefore, we can conclude that different forms of culture and knowledge may have the same recognised interdisciplinary value and world-wide prestige.
\end{abstract}

Key words: interdisciplinarity, traductology/translemics, linguistics, artistic discourse.

Sumario: 1. Introducción. 2. Revisión metodológico-científica actual de los términos 'discurso', 'traductología/translémica', 'arte', 'arte poética', 'sociología del arte’ y 'discurso artístico. 3. La reciente investigación interdisciplinar en las ciencias humanas: su influencia decisiva en la traductología/translémica, la lingüística aplicada y el discurso artístico. 4. Aproximaciones y diferencias entre los discursos artístico-literario, científico-técnico, didáctico-lingüístico y traductológico. 5. Conclusiones.

\title{
1. Introducción
}

La historia, la literatura, la traductología y el arte universal nos ilustran constantemente de que, pese a frecuentes circunstancias adversas -recordemos el caso de Sócrates, acusado por la envidia de sus contemporáneos de no acatar a los dioses nacionales, siendo por ello condenado a beber la letal cicuta-, los cánones eternos de la estética y el rigor científico se han mantenido casi siempre vigentes. Del mismo modo, la incomprensión y los celos se cebaron también con científicos (Galileo y Copérnico), compositores (Mozart y Salieri), escritores (Shakespeare y Cervantes), pintores (El Greco), filósofos, teólogos y traductores (Fray Luis de León, encarcelado por verter al castellano el Cantar de los Cantares). En Francia, Jacques Lefèvre d'Étaples y Climent Marot fueron incansablemente perseguidos y vilipendiados por lo que algunos corruptos fanáticos de la época consideraron polémicas traducciones.

Hemos constatado, tras haber consultado amplia bibliografía, que la investigación interdisciplinar en el campo de la lingüística, la traductología/translémica, el arte o la ciencia en general, suele llevar implícito un gran esfuerzo mental y, en ocasiones, como acabamos de señalar, incluso un penoso sufrimiento físico. No obstante, si el artista, el traductor, el intérprete o el científico consiguen que sus naves llegen a buen puerto, la satisfacción resultante les compensará de todos los males, 
haciéndoles olvidar los sinsabores habituales de la vida profesional. Sírvanos de paradigma Santiago Ramón y Cajal : "Este placer inefable, al lado del cual los demás deleites se reducen a pálidas sensaciones, que indemniza al estudioso o al investigador de la penosa labor analítica"1

Pese a los memorables descubrimientos de otras épocas, nunca como en el último tercio del siglo XX e inicios del actual, la investigación, en el ámbito de la traductología/translémica y otras ciencias auxiliares, ha alcanzado, con la aplicación de las nuevas tecnologías, niveles tan altos de rigor científico-técnico interdisciplinar, fruto del esfuerzo titánico de universidades e instituciones culturales de gran prestigio -Harvard, Yale, Georgetown, Oxford (donde iniciamos el estudio del tema que nos ocupa), Cambridge, Technical Institute of Massachussets, Complutense y UNESCO, entre otras-, recomendando la exaltación de la ética profesional y de los valores humanos, tan denostados hoy en día. Además, insisten, en que, en el ámbito de la investigación interdisciplinar, las naciones deberían respetar su valioso patrimonio cultural y el no menos importante reducto de los 'pequeños detalles' y 'cosas sencillas' de la vida cotidiana, antaño ensalzados por Ortega y Azorín, para así mejorar algunos de los males que aquejan a la enfermiza sociedad de comienzos del siglo XXI, tan tristemente afectada por las fuerzas de la naturaleza, el terrorismo, el hambre, las pandemias, las guerras, el paro creciente y la caótica situación económica mundial.

\section{Revisión metodológico-científica actual de los términos 'discurso', 'traductología/translémica', 'arte', 'arte poética', 'sociología del arte' y 'discurso artístico'}

El Diccionario de la Lengua Española de la Real Academia define el 'discurso', como "serie de palabras y frases empleadas para manifestar lo que se piensa o siente". Tras exhaustiva investigación, valiéndonos del método científico, la observación y las opiniones de varios autores, coincidimos con J.H. Habermas y Guy Cook, cuando el primero afirma que "en el discurso tiene lugar un entendimiento comunicativo sobre contextos de sentido preconcebidos ingenuamente, en torno a aquello que consideramos comprensible y razonable", 2 en tanto que el segundo, en Discourse, puntualiza que "discourse analysis examines how stretches of language, considered in their full textual, social and psychological context become meaningful and unified for their users"3. Igualmente, hemos constatado que los nuevos enfoques de Cook en Applied Linguistics (2003) y de A. Davies y C. Elder en The Hand Book of Applied Linguistics (2006), se centran en los grandes avances de la lingüística aplicada, la traductología, los estudios de interpretación y la didáctica de las lenguas modernas, todo ello inserto en un vasto ámbito interdisciplinar.

\footnotetext{
1 Ramón y Cajal, S., Reglas y Consejos sobre la Investigación Científica. Beltrán: Madrid 1940, $20-22$.

2 Habermas, J.H., cit. por Theodor Lewandowski, en: Diccionario de Lingüística. Madrid: Cátedra 1992, 102.

3 Cook, G., Discourse. Oxford: Oxford University Press 1989, «Introduction», 3. Del mismo autor: Applied Linguistics, Oxford: Oxford University Press 2003.
} 
En el terreno de la 'traductología/translémica', la mayoría de los eruditos ponen de manifiesto la plena satisfacción que una buena traducción puede reportar al que la lleva a cabo. Nuestra labor investigadora nos ha conducido a analizar la obra de algunos escritores que impulsaron su creatividad traduciendo a otros: por ejemplo, los clásicos castellanos compilados en la Biblioteca de traductores españoles por Marcelino Menéndez Pelayo (traductor de textos griegos, latinos, italianos, franceses e ingleses). Anteriormente, Quevedo y Lope de Vega hicieron hábiles escarceos en el terreno de la traducción, si bien, las figuras señeras fueron Fray Luis de León (traductor del hebreo, griego, latín e italiano) y Fray Luis de Granada quien, al modelar su prosa española sobre la latina, recibió el apelativo de "Cicerón castellano". Pese a todo, hemos constatado que en España, hasta épocas recientes, la traducción no siempre ha sido apreciada en su justa medida como sí ha venido ocurriendo en otras latitudes.

Para el recientemente fallecido Valentín García Yebra, la penosa infravaloración de nuestros traductores ha tenido su contrapunto en la estima de la que otros han gozado en el resto de Europa, sobre todo, en Alemania, donde Goethe la encumbró, afirmando Novalis, en 1797, que "no hay ningún escritor alemán importante que no haya hecho traducciones y que no se haya preciado de ellas tanto como de sus obras originales" 4 . En el ámbito de la literatura hispanoamericana, la escritora Ana Gargatagli señala que "Miguel Ángel Asturias, Borges, Cortázar (traductor oficial de la UNESCO durante varios años) y Mújica Laínez, se han interesado por la traducción, renovando y actualizando así el lenguaje literario en toda Hispanoamérica"s.

Coincidimos plenamente con la tesis de J.C. Santoyo y R. Rabadán, en su artículo "Traductología/translémica: una nueva disciplina lingüística" (1990), cuando concluyen que "los estudios de traducción de condición teórica se han convertido en uno de los campos más dinámicos de la investigación lingüística" ". En noviembre de 1982, ambos presentaron al Comité organizador del Primer Congreso Nacional de Lingüística Aplicada su comunicación "A propósito del término translema", leyéndola en abril de 1983 en la universidad de Murcia, donde trataron unas unidades de traducción a las que llamaron "translemas", y de ahí el nombre posterior de 'translémica'. Lo mismo ocurrió en Bruselas, en el verano de 1984, ante el Congreso Internacional de Lingüística Aplicada; finalmente, en diciembre de ese mismo año, Annie Brisset defendía en Canadá, en su artículo "Étude d'un translème", "la science qui dans $1^{\prime}$ avenir s'appelera peut-être translemique.... ${ }^{7}$, temas todos ellos ya tratados en nuestra tesis doctoral La investigación interdisciplinar en historia y lingüistica: estudio de metodologías contrastadas (Universidad Complutense de Madrid, 1995).

4 Carta a August Wilhem Schelgel (30-11-1797). Citado en García Yebra, V., En torno a la traducción. Madrid: Gredos 1983, 329.

5 Gargatagli, A., «Traducción y Creación», Cuadernos de Traducción e Interpretación (1984), 137-142.

6 Santoyo, J. C., y Rabadán, R., «Traductología/translémica: una nueva disciplina lingüística», Revista Española de Lingüística Aplicada Anejo I (1990), 143.

7 Brisset, A., «Étude d'un translème», Meta 7 (1984), 25-26. 
En la actualidad, los lingüistas que investigan la traductología/translémica, prestan suma atención a la 'lengua meta' o 'de llegada', afirmando P. Newmark que "all translation problems are finally problems of the target language" mente de acuerdo con Newmark, a lo que añadimos que, en nuestra opinión, los oficios de traductor e intérprete benefician siempre en grado sumo a quienes los ejercen, ya que amplían su léxico y forma de pensar, enriqueciendo sus mentes y habilidades traductoras e interpretativas. A lo anterior, T. Gibert agrega que "la traducción estimula un rastreo constante en pos de la palabra más adecuada dentro del contexto", en tanto que J.C. Richards y R. Schmidt concluyen que "translation is the process of rendering written language from the source language into the target language... 'translation' refers to transfer between written texts, and 'interpretation' to transfer a spoken message from one language to another" 10 .

Analizando estadísticas y traducciones diversas, hemos constatado que los estudios actuales de traductologíaltranslémica están impulsando la búsqueda constante de recursos morfológicos, sintácticos y fonológicos poco usuales en la propia lengua. Además, al tener que adaptar tecnicismos complejos, los traductores e intérpretes deben conocer hoy las llamadas reglas de derivación y ser hábiles con arcaísmos y neologismos, considerando también las dificultades sintácticas que puedan surgir en las traducciones literarias, sobre todo, en poesía, problemas que les crearán serios quebraderos de cabeza, si bien les premiarán con el reconocimiento público una vez resueltos. En cuanto a la traducción de onomatopeyas, opinamos que, a menos que estén consagradas por el uso cotidiano -como es el 'canto del gallo'-, también pueden llevar a traductores e intérpretes a situaciones ridículas, siempre que no se apliquen buenas dosis de sentido común. Finalmente, V.G. Yebra ${ }^{11}$, recomienda la 'traducción comunicativa'-tanto en prosa literaria como artística-, aquella que intenta producir en el lector o espectador un efecto igual al de la versión original, postergando la 'traducción semántica', ya que cada lengua posee recursos específicos para expresar determinados registros.

Citemos ahora el caso de un profesional cuya misión sea verter al español el texto de una obra teatral o cinematográfica inglesa, con abundantes términos del habla vulgar londinense (por ejemplo, la confusión frecuente entre el artículo inglés 'the' y el pronombre personal 'them', o bien, diversos errores sintácticos y fonéticos). Utilicemos como paradigma la película "My Fair Lady", dirigida por George Cukor, con Rex Harrison, como Professor Higgings, solterón empedernido exigente y gruñón, y Audrey Hepburn, en su papel estelar de Lisa Doolittle, florista pobre callejera en el antaño abigarrado mercado de flores londinense, junto al célebre Covent Garden, donde el público aristocrático de la era victoriana acudía a lucir sus

\footnotetext{
8 Newmark, P., Manual de Traducción. Madrid: Cátedra 2004, 25.

${ }^{9}$ Gibert, T., «Las prácticas de traducción y el proceso de adquisición de la L1», en: Actas del VI Congreso Nacional de Lingüistica Aplicada. Santander: Universidad de Santander 1988, 272.

${ }^{10}$ Richards, J.C. / Schmidt, R., Longman Dictionary of Language Teaching and Applied Linguistics, Pearson Education: Essex 2002, 563.

${ }^{11}$ Yebra, V. G., «Traducción y enriquecimiento de la lengua propia», en: Actas del XIII Congreso Internacional de Lingüística "En torno a la traducción”. Québec: Universidad de Québec 1971, 91-104.
} 
mejores galas y a disfrutar con las óperas de Verdi, Puccini, Bellini y otros famosos compositores. Lisa, condicionada socialmente por su humilde origen y por su fuerte acento cockney, acude al Profesor Higgins para que mejore su inglés y la haga parecer una 'real lady', capaz de pronunciar correctamente la frase "The rain in Spain stays mainly on the plain"...El traductor encargado de dicho guión teatral o cinematográfico, junto con los expertos en doblaje ('dubbing'), deberán utilizar los recursos castellanos equivalentes a los ingleses de zonas oprimidas de la capital británica, donde resulte habitual, como en cualquier ciudad española, el uso del laísmo -'la dije'-, la 's' unida a la segunda persona del pretérito indefinido - 'estuvistes'-, a un nombre -'un taxis'-, o las terminaciones en 'ao' -'estao'- en lugar de 'estado', lográndose así una traducción cercana y ajustada al original.

Nuestra investigación científica interdisciplinar nos lleva ahora a centrarnos en el término 'arte', como "acto mediante el cual una persona, valiéndose del objeto, de la imagen o del sonido, expresa lo material o lo inmaterial, creando siempre, sin importar lo que se copie o fantasee". Para Pío Baroja, 'arte' era la habilidad o maña con que se hacía algo: "Sólo algunos mechones de pelo blanco en las sienes, ocultados con arte, podían denunciar la edad". Al hablar de 'arte poética', nos referimos al título de algunas obras didácticas en que se definen las características de la creación poética, dándose a conocer las reglas a observar, en tanto que la 'sociología del arte' implica una visión más amplia del concepto artístico, nacida en el siglo XIX de las filosofías idealista y positivista, investigando Hegel las correlaciones entre la obra artística, sus interpretaciones y las ideas generales de una época. Al filósofo francés M. J. Guyau, tal unión interdisciplinar le hizo considerar el arte como "lenguaje universal, favorecedor de comunicaciones profundas entre todos los seres humanos", a lo que nosotros añadimos: "traductor e intérprete de la belleza emocional e intuitiva de la humanidad".

Recientemente, en la revista El Cultural, del Diario El Mundo, se preguntaba al escritor P. Gimferrer su opinión sobre la 'incidencia del arte y la poesía en la sociedad actual', respondiendo éste que "ambos son una interpretación intensa y única de la realidad, de la experiencia vital acumulada"12. En la actualidad, la llamada 'sociología del arte' está descubriendo formas de lo imaginario arraigadas en nuestra existencia de grupo, destacando los trabajos de tecnología artística, de M. Griaule y J. Laude, sobre las metamorfosis de la sensibilidad colectiva. A lo largo de nuestra investigación hemos ido descubriendo que en el 'discurso artístico literario' actual late un fondo de espontaneidad personalista, resistente al quehacer académico, siendo la habilidad menos transmitida como enseñanza y, por tanto, no aprendida a priori. Además, hemos comprobado que dentro del vasto campo de la creación literaria, pictórica, musical y escultórica de la sociedad postindustrial, destaca la persona hecha a sí misma -artista, traductor o intérprete, la que lucha por mejorarse, con sus propias virtudes y defectos. Para K. Worth, uno de los aspectos más relevantes vinculado a este terreno es la notable reciprocidad entre guionistas, traductores, intérpretes, expertos en doblaje, tramoyistas, pintores y decorados que se les

${ }^{12}$ Gimferrer, P., «Letras», El Cultural, Diaro El Mundo (junio de 2010), 9. 
encargan para determinadas producciones teatrales, cinematográficas y operísticas, afirmando que, en dichos ambientes, "one begins to lose the sense of plays, pictures and poems del having de la separate identities" 13 .

Si ahora analizamos los conceptos del 'arte'y de la 'traductología' en su sentido originario, percibimos que se encuentran interrelacionados con la 'técnica', la cual sirve para 'dar a luz un nuevo ser'. Inicialmente, la técnica artificial y la creación artístico-literaria estuvieron muy ligadas, pese a que hoy sufran una cierta ruptura. Además, la producción técnica de nuestro tiempo, forjada a base de estudios científicos previos, se rige por múltiples intereses: económicos, políticos y militares, para así obtener el poder sobre la naturaleza, salvo penosas excepciones como el reciente caos ocurrido en Japón (marzo 2011), por un terremoto-tsunami, con graves daños y riesgos en las centrales nucleares del país. Pese a todo, las creaciones artísticas sólo son una mera expresión del arte pictórico, escultórico o literario, independientemente de las técnicas mecánicas, opinando M.García Morente que "una poesía puede ser elegante, una traducción perfecta, un lienzo impresionarnos y una sinfonía deleitarnos, pero no serán obras de arte si les falta la chispa del genio, lo que Kant llamó el espíritu"14

Compartimos la tesis de S.M. Plaza cuando estudia el discurso artístico en la traducción literaria, afirmando que "my basic idea is that, in this case, translation should be discourse-oriented and not a sentence or even word-oriented process" 15 . Igualmente, coincidimos con Christiane Nord cuando aconseja a traductores e intérpretes que respeten al máximo la 'functionality plus loyalty', es decir, que se ajusten y atengan al riguroso concepto de 'funcionalidad más lealtad' al autor de la versión original ${ }^{16}$; inteligente recomendación que, de cumplirse, evitará serios malentendidos, pérdidas de tiempo y hasta de empleo, e infinidad de males mayores que pueden llegar a ser irreparables.

\section{La reciente investigación interdisciplinar en las ciencias humanas: su influencia decisiva en la traductología/translémica, la lingüística aplicada y el discurso artístico}

Varios asesores y expertos del Departamento de Ciencias Sociales de la UNES$\mathrm{CO}$ han reiterado constantemente los beneficiosos efectos que la interdisciplinariedad puede tener, como herramienta de suma utilidad para el investigador científico, junto con su decisiva aportación para las ciencias del hombre. Ya en el X Congreso Internacional de Lingüistas (Bucarest, 1967) se analizaron en profundidad las conexiones entre las ciencias del lenguaje y otros saberes, consolidándose posteriormente la importancia del factor interdisciplinar en el discurso literario y artístico, con

13 Worth, K., The Irish Drama of Europe from Yeats to Beckett. Londres: The Athlone Press 1978, 53.

${ }^{14}$ Kant, I., Crítica del juicio. Edición de M. García Morente. Madrid: Espasa Calpe 1990, 42.

15 Plaza, S. M., «Discourse Analysis in Literary Translation», Estudios de Filología Inglesa. Homenaje a Jack White. Madrid: Universidad Complutense de Madrid 2000, 162.

${ }^{16}$ Nord, Ch., Text Analysis in Translation: Theory, Methodology, and Didactic Application of a Model for Translation-Oriented Text Analysis. Amsterdam: Rodopi 1991, 125. 
autores de la talla de Régine Robin, en Francia (Histoire et Linguistique, 1973), y Robert Hodge (Literature as Discourse. Textual Strategies in English and History, 1990) -donde los textos literarios se estudiaron en función de diversos aspectos sociales y culturales-, o Pierre Bourdieu (The Rules of Art. Genesis and Structure of the Literary Field, 1996), obra que cita las normas por las que debe regirse el discurso artístico-literario internacional.

En el terreno histórico-lingüístico español, el libro Teoría del discurso historiográfico, hacia una práctica consciente de su método (1991), de B. Escandell, nos ofrece, con metodología científica sumamente innovadora, una brillante visión de la historia como resultado de un sistema orgánico de factores interdependientes -hombres, medio natural, relaciones sociales, textos traducidos de otras épocas y culturas, arte, ciencia y técnica-, unitariamente articulados. La investigación del discurso artístico cobra aquí un carácter hermenéutico al analizar el autor contenidos histórico-lingüísticos relevantes, explicando su significado real, centrado en la correcta traducción e interpretación de textos antiguos, facilitando así la comprensión de dicho discurso como sucesión de sincronías ${ }^{17}$.

Con el fin de reafirmar la base sobre la que estamos realizando nuestra investigación interdisciplinar, citamos a continuación el Dictionary of Language Teaching \& Applied Linguistics (Longman, 1993:19), donde se establece que: "Applied linguistics is the study of language and linguistics in relation to practical problems, such as Lexicography, Translation and Speech Pathology, using information from sociology, psychology, anthropology and linguistics in order to develop its own theoretical models of language use". A lo anterior, añadiremos que tanto la 'lingüistica aplicada' como la 'traductología/translémica' han jugado un papel primordial en las correlaciones entre las ciencias humanas, debido a la estructura autónoma del lenguaje y a su impacto en los distintos estamentos culturales. Dentro de este orden de cosas, el antropólogo D.H. Hymes, en The Ethnography of Speaking, califica a la lingüística como "una de las ciencias más adelantadas", tildándola de "modelo metodológico ejemplar'18.

En cuanto a la articulación de las ciencias del hombre y las de la naturaleza, hemos constatado que las primeras lo han hecho en una serie bastante análoga a la que ha reunido a las ciencias naturales, entendiéndose los 'lenguajes formalizados', aplicados al mundo científico y técnico, como "transformaciones del lenguaje natural". Por su parte, Z.S. Harris, en Mathematical Structure of Language, puntualiza que "el lenguaje formalizado más perfeccionado es el de las matemáticas, ya que brinda un 'metalenguaje multiforme' capaz de traducir datos lingüísticos, aplicando la teoría de los conjuntos a la gramática y a la traducción e interpretación"19.

Coincidimos con R. Jakobson cuando defiende la tesis de que "el análisis del arte verbal cae dentro de la competencia inmediata del lingüista, obligándole a una atención continuada en torno a las complejidades de la poética, como estudio de la función artística de los sistemas semióticos en general"20, en tanto que la 'semióti-

17 Escandell, B., Teoría del discurso historiográfico. Hacia una práctica consciente de su método. Oviedo: Universidad de Oviedo 1991, 33-34.

18 Hymes, D. H., «The Ethnography of Speaking», American Anthropologist 23 (1964), 90.

19 Harris, Z. S., Mathematical Structure of Language. New York: Rowledge 1968, 25-50.

20 Jakobson, R., Nuevos Ensayos de Lingüística General. Madrid: Siglo XXI 1976, 36. 
$c a$ ' sirve para establecer comparaciones en la formulación y envío de mensajes, centrándose la 'lingüística' en la comunicación de los lenguajes verbales. Nuestra investigación sobre las 'conexiones entre economía, estadística y lingüística aplica$d a$ '-tomando como base la obra Statistics in language studies, de A. Woods, P. Fletcher y A. Hughes (Cambridge University Press, 1986)-, nos ha llevado a concluir que éstas han existido siempre, habiendo ya sido tratadas por el propio Adam Smith, en $A$ dissertation on the origin of languages ${ }^{21}$. Curiosamente, más cercano a nosotros, Talcott Parsons, en "Systems Analysis: Social Systems", considera las 'transacciones económicas' como "tipos de conversación hechos con arte y habilidad"22, aunque hoy ese arte prácticamente ha desaparecido, salvo honrosas excepciones, imperando en dichas conversaciones la crispación y la agresividad, sin apenas dar pie al diálogo creativo y respetuoso.

Dentro del núcleo interdisciplinar de las ciencias humanas y del discurso artístico, la 'psicología del lenguaje' investiga la conducta lingüística con métodos psicológicos, fomentando su estructuración en el seno de la psicolingüística, encargándose el psicoanálisis de impulsar la exteriorización del lenguaje interior. A este respecto, el psiquiatra español Enrique Rojas ha afirmado recientemente que la universidad de Cambridge es una de las más avanzadas en el estudio del cerebro humano y en neurolingüística, destacando su obra Linguistics: the Cambridge Survey. En lo que concierne a la 'retórica', la mayoría de los autores estiman que ésta funciona como teoría y técnica del discurso orientado siempre al receptor: "ganarse las almas de los hombres por medio de las palabras", según el propio Platón, siendo su interés más reciente, político, económico, artístico y publicitario. Para J. Durán, es "el arte de la palabra fingida", pudiendo esgrimirse como crítica contra algunos personajes del espectro político internacional, ${ }^{23}$ opinando lo mismo J. Charteris Black en Politicians and Rhetoric. The Persuasive Power of Metaphor (Hampshire \& New York: Palgrave Macmillan, 2005).

Actualmente existen múltiples nexos entre la 'lingüistica', la 'traductología' y la 'informática' ya que en el ordenador introducimos una cadena de símbolos (input), elaborados en base a reglas almacenadas (program), produciéndose otra cadena (output). Para J. Lyons, estas tres fases (input, program y output) suponen el fundamento de la comunicación. Paralelamente, M. Alvar, en Del Glosario al Diccionario, estima que el problema de la 'traducción automática' estriba en el matiz "artístico-espiritual", imposible de traducir, recomendando dotar a las máquinas de medios que identifiquen unidades lingüísticas más allá de las simples palabras ${ }^{24}$. Por su parte, S. Laviosa-Braithwaite aplica la informática al complejo campo de la traducción, puntualizando que "there seems to be little doubt that computer-assisted

${ }^{21}$ Smith, A., Dissertation on the Origin of Languages. Comentado por E. Coseriu. Tubinga: Universität Tübingen 1970, 24.

22 Parsons, T., «Systems Analysis: Social Systems», en: International Encyclopaedia of the Social Sciences. Nueva York: Rowledge 1968, 342.

${ }^{23}$ Durán, J., Retórica e imagen publicitaria. Madrid: Gredos 1982, 81-115.

${ }_{24}$ Alvar, M., «Del Glosario al Diccionario», Boletín de la Academia Puertorriqueña de la Lengua Española VII (1979), 71-91. 
translation is rapidly becoming the norm rather than the exception" ${ }^{25}$, en tanto que para D. Crystal: "the Internet has been an extraordinary rapid communication revolution... the Web is more a social creation than a technical one"26.

En el año 2011, el output del Servicio de Traducción de la Comisión Europea (conocido por sus iniciales francesas SDT), se ha acercado a unos cuatro millones y medio de páginas de texto estándar, siendo redactadas en lengua inglesa tres quintas partes de los documentos que dicho Servicio recibe anualmente. Según un estudio realizado por el Instituto Cervantes: del 2002 al 2010, la presencia del español en diversas revistas de ciencia y tecnología, ${ }^{27}$ sólo ha supuesto un $0,4 \%$ de la producción científico-tecnológica internacional; el italiano, un $0,2 \%$; el francés, un $0,9 \%$; el alemán, un $1,2 \%$, y el inglés, un $90 \%$, con un incremento sostenido a lo largo de todo el período, lo cual pone de manifiesto, como afirma T.A. Van Dijk, en su obra Discourse and Power (Palgrave Macmillan. New York, 2008), el auge creciente del inglés debido al poderío expansionista político y económico norteamericano.

Resumiendo, la realidad actual nos muestra que las ciencias sociales están influyendo progresivamente en la evolución de las disciplinas científicas y en el entorno específico de cada una de ellas, afectando a sus discursos e impulsando el uso de nuevas tecnologías, estrategias inteligentes y hasta métodos de marketing para la divulgación de sus descubrimientos, todo ello con un señalado carácter interdisciplinar. A este respecto, Ruggiero Romano nos recuerda que algunos conceptos de las matemáticas ya están siendo reciclados y empleados en las llamadas ciencias del hombre (Poulet, Ecco y Tom); por ejemplo, en los casos concretos de 'centrado/ acentrado' y 'local/global', conceptos que servirán para posibilitar la renovación de la investigación del discurso, como medio de comunicación entre diversas ramas del conocimiento científico-técnico de nuestro siglo. ${ }^{28}$

\section{Aproximaciones y diferencias entre los discursos artístico-literario, científico-técnico, didáctico-lingüístico y traductológico}

La idea, generalmente aceptada, y que hemos rigurosamente comprobado en nuestra investigación, es que sí existen aproximaciones y similitudes entre dichos tipos de discurso, aunque también hemos podido observar distanciamientos y diferencias, ya que, en determinadas circunstancias, al discurso artístico-literario no le es asignable el paradigma de la emoción estética, en tanto que al científico-técnico le suele acompañar la honestidad del investigador, por lo que las revoluciones científicas no son declaradamente escandalosas pero sí pueden sorprendernos por su 31.

${ }^{25}$ Laviosa-Braithewaite, S., «Computers and Translators», The European English Messenger 7 (1996),

${ }^{26}$ Crystal, D., Language and the Internet. Cambridge: Cambridge University Press 2002. «Preface», vii, viii, ix.

${ }_{27}$ Revistas de las ocho bases internacionales de datos (Inspec, Compendex, Medline, Biosis, Chemical Abstracts, Enviroline, Georef y Agrícola) 2010.

28 Aquí se defiende una "metadisciplinariedad", un intercambio de lógicas. 
amplia repercusión internacional y enorme impacto social. Queremos además destacar que el uso de las 'metáforas' no resulta siempre correcto; sobre todo, hemos comprobado penosos errores en el campo de la traducción de textos literarios e incluso en el ámbito de la interpretación, afirmando A.M. Municio que, a pesar de que Hobbes quiso confinarlas a los limitados recintos lingüísticos, ha ocurrido justo todo lo contrario, resultando imprescindibles en el discurso técnico y participando plenamente del pensamiento científico.

Por otra parte, hemos constatado que en el terreno de la metáfora, lo invisible puede convertirse en realidad creativa artística, siendo éste el caso del uso del círculo en los ciclos bioquímicos, fisiológicos y termodinámicos; el reduccionismo de la máquina en las ideas químicas de Pasteur, o bien, la bellísima Venus del Espejo, único desnudo integral de Velázquez, una de las obras maestras más admiradas en Londres. Con respecto a este lienzo, opinamos que si un sencillo espejo ha inspirado magníficas creaciones artísticas, su extensión metafórica también ha servido para diseñar conceptos útiles de la química, mundos oníricos de la biología y fantasías literarias en Lope de Vega: "Es como espejo la cara / adonde el alma se mira. / La pena como el amor como la ira, / en su cristal se mira" 29 . Finalmente, P. Newmark concluye que "the translation of any metaphor is the epitome of all translation, in that it always offers choices in the direction either of sense or of an image, or a modification of one, or a combination of both" 30 .

En cuanto al 'discurso didáctico-lingüístico', centrado en la enseñanza de idiomas y en el estudio de la lingüística aplicada, los avances han sido espectaculares desde épocas lejanas: ya los romanos daban prioridad al uso del griego, cautivados por los relatos épicos de Homero en La Ilíada y La Odisea, o por los sublimes mensajes estético-escultóricos de Fidias y Praxíteles. Además, en las villas de los patricios era habitual la presencia de instructores extranjeros para que enseñaran a sus hijos la cultura y la lengua de sus países de origen. No obstante, el camino recorrido hasta la actualidad ha sido complejo, tortuoso y ambiguo, si bien sumamente útil y gratificante, agilizándose el proceso mediante la adaptación continua de la lingüística y de los métodos de enseñanza y traducción de lenguas a las circunstancias políticas, sociales, culturales y artísticas de cada país en determinados momentos históricos. Para A. S. Pérez, "conocer el pasado histórico-lingüístico, artístico-literario y científico-técnico es la mejor garantía de comprensión del presente" ${ }^{31}$, recomendando el novísimo 'método integral' en los estudios de traducción, interpretación y didáctica de las lenguas modernas, donde tienen cabida estrategias de métodos anteriores (el de 'lectura y traducción', el 'directo' y el del 'silencio' de Gategno), junto con los posteriores ('nocional', 'funcional' y 'comunicativo'), para así llegar a la 'etapa post-comunicativa', que nosotros denominamos 'ecléctica-integral', en base a su diversidad estratégico-metodológica y a su encomiable amplitud de miras.

${ }^{29}$ Municio, A.M., «El Espejo», Prensa Española (02/02/1993).

${ }^{30}$ Newmark, P., op. cit., 113.

31 Pérez, A. S., Hacia un método integral en la enseñanza de idiomas. Madrid: SGEL 1994, 54. 
Centrándonos ahora en la 'traducción' y en las características más relevantes del 'discurso traductológico', debemos señalar que aquélla ya cuenta con una historia propia desarrollada en épocas sucesivas, cada una más breve que la anterior, dado que también aquí la "aceleración histórica" ha marcado su fiel impronta, afirmando J. C. Santoyo, que "el paso de una etapa a otra se produce como consecuencia de la aparición de un nuevo factor que, sin suprimir nada previo, modifica notablemente la trayectoria general de este afán, estudio, arte y profesión"32. Para A. H. Albir, "la traducción es un saber hacer que consiste en resolver los problemas que se plantean en cada caso [...] En cambio, la traductología es un saber sobre la práctica traductora $[\ldots]$ una disciplina científica que necesita entablar relaciones con otras muchas" $" 33$.

Del amplio objeto de estudio de la nueva traductología/translémica derivan dos características esenciales: la multidisciplinariedad y la necesidad de encuadrarse dentro de un marco metodológico propio; razón por la cual el traductor deberá buscar ayuda en las llamadas 'ciencias auxiliares instrumentales', que le servirán de apoyo en su trabajo, entendiendo por tales: la sociología, la antropología, la psicología, la historia, la lingüística, la crítica literaria, la informática y la pedagogía, todo ello en función de cuáles sean los objetivos específicos de su vida profesional (traducción literaria, traducción audiovisual o didáctica de la traducción como tal).

En lo que respecta a las 'diferencias entre los discursos', nuestra investigación se ha llevado a cabo teniendo en cuenta el modo distinto de incidir el 'tiempo', considerando que la creación científica sólo está dotada del ritmo del cambio y del progreso, y que su mayor caudal se ubica en las fases cronológicas del futuro. Paralelamente, asistimos hoy al fenómeno del 'envejecimiento', por el que, en algunas parcelas del saber, diez años equivalen a siglos de pasividad en otras ramas del conocimiento, careciendo aquí la regresión de sentido para los científicos. Pese a todo, opinamos que en la creación artística, al igual que ocurre, aunque en menor escala, en la vida profesional de escritores, traductores e intérpretes, cuando la genialidad de la persona se ve inspirada por fuerzas sublimes, siempre cabe la posibilidad de que se produzca el sortilegio mágico de sobreponerse al tiempo, con lo cual su obra llegará incluso a alcanzar el cenit de la belleza inmortal.

Finalmente, tras haber resumido las aproximaciones y diferencias más notables entre los diversos tipos de discurso, estimamos oportuno citar el artículo "La línea secreta", de J. R. Carballo, de la Real Academia Española de la Lengua, donde nos recuerda que "desde hace décadas, el mundo de las ideas ha acelerado su marcha, abriendo horizontes prometedores $[\ldots]$ ¿Es posible descubrir la línea secreta que une el caos y un orden nuevo, el surgir de una mentalidad insospechada?...". Estamos convencidos de que dichos horizontes y ese novísimo orden están influyendo, de

\footnotetext{
32 Santoyo, J. C., Teoría y crítica de la Traducción: Antología. Barcelona: Universitat Autónoma de Barcelona 1987, 36.

33 Albir, A. H., Traducción y Traductología. Introducción a la Traductología, Cátedra: Madrid 2001, 25.
} 
manera decisiva, en las formas de expresión interdisciplinar de los discursos ya citados, y probablemente sigan haciéndolo abiertamente en el futuro ${ }^{34}$.

\section{Conclusiones}

Una vez analizado todo lo anterior, podemos afirmar que los diversos tipos de discurso son hoy en día tema central de investigación en trabajos de alto nivel científico, como el de Concepción Maldonado, en su obra Discurso directo y discurso indirecto, donde, partiendo de la reciente lingüística norteamericana, establece una diferenciación innovadora entre los 'discursos naturales' -aquellos en que el hablante real dice algo en un lugar también real-, y los 'discursos ficticios' -enunciados con pronombres de segunda persona, en los que se alude al no receptor de la situación de enunciación-. La aportación investigadora más valiosa de C. Maldonado ha sido facilitarnos el llamado 'estilo indirecto libre', en el que los hechos lingüísticos quedan condicionados por la necesidad de comunicación, siendo el hablante el creador al que se han venido refiriendo los idealistas ${ }^{35}$.

Fruto de nuestra labor investigadora ha sido comprobar, mediante la aplicación del método científico, el estudio de diversas estadísticas y la consulta bibliográfica internacional, los avances espectaculares llevados a cabo por la investigación centrada en torno a los cuatro tipos de discurso citados, todo ello con el mérito añadido de la actual crisis económica internacional, que tanto está afectando a las dotaciones de los equipos investigadores. No obstante, los resultados están siendo muy alentadores, habiéndose profundizado con éxito en aspectos que hasta ahora sólo habían sido ligeramente esbozados: por ejemplo, las reiteradas alusiones de Humberto López Morales al auge creciente de los factores culturales, artísticos, lingüísticos, sociológicos y psicológicos del lenguaje, y a su incidencia favorable a la hora de impulsar nuevos proyectos de investigación en el terreno de la traducción, interpretación y el uso de las nuevas tecnologías en la didáctica de las lenguas modernas.

Concluyendo, un hecho indiscutible es, como ya apuntábamos al inicio, el de las enormes trabas y dificultades que traductores e intérpretes han tenido que afrontar y superar desde tiempos tan remotos como el Egipto faraónico, y que, para algunos, aún siguen siendo suplicio tantálico inconfesable. A este respecto, C. Distante opina que "sólo cuando tengamos una verdadera historia de la traducción y de la interpretación, sabremos lo indispensable que éstas han sido para la comprensión entre pueblos con distintas lenguas" ${ }^{\prime 36}$. Actualmente, hemos podido corrobarar, mediante informes comunitarios fiables, que, en una Unión Europea políglota y multicultural, la traductología/translémica ha pasado a ocupar un primerísimo plano, con grupos minoritarios que 'traducen' a las culturas dominantes, produciéndose una absorción recí-

34 Carballo, J. R., «La línea secreta», Prensa Española. Madrid (23/06/1992).

35 Maldonado, C., Discurso directo y discurso indirecto. Taurus: Madrid 1991, 17-23.

36 Distante, C., «L'importanza della traduzione nel mondo di oggi», Traduçao e Comunicaçao 7 (2010), 15. 
proca entre las partes, afirmando S. Stephanides que "tanto las relaciones históricas entre traducción y tradición como la autoridad del traductor, han impulsado la relación existente entre el factor cultural y la traducción como tal"'37. Recordemos ahora que el período postcolonial y la creciente intercomunicación mundial han supuesto un cambio sumamente notable para el legado cultural europeo, similar al que tuvo lugar tras el Humanismo y el Renacimiento; además, el poder crecientemente expansionista de los Estados Unidos en estas últimas décadas y la globalización del conocimiento, han favorecido el que la comunidad científica internacional se haya decantado mayoritariamente por las traducciones al inglés como lengua franca.

E. Bernárdez, en El lenguaje como cultura. Una crítica del discurso sobre el lenguaje (2008), afirma que "desgraciadamente, la globalización es la imposición de un determinado sistema político y económico, unos determinados valores culturales y una determinada lengua [...] Así, perderá sentido el discurso sobre las culturas estatales, nacionales y regionales, en una cultura global en proceso de construcción acelerada" ${ }^{38}$. Ahora bien, otra conclusión a la que hemos llegado en nuestra investigación, es que frente al fenómeno de la globalización, algunas sociedades reclaman hoy autonomía y el derecho a expresarse en su propia lengua, sirvan de paradigma los casos de China e Indias, lo cual supone, en el ámbito científico-técnico, la traducción a gran escala, la acuñación de términos nuevos y la creación rápida de neologismos. Todo ello servirá de ayuda para transvasar el contenido innovador del texto de origen al texto meta en las sociedades menos desarrolladas, convirtiéndose éstas en receptoras de préstamos culturales, científicos y lingüísticos. En nuestro mundo global, la reciente terminología técnica ya forma parte de los llamados 'lenguajes especializados'o 'restringidos' en cuanto a la situación comunicativa, entendiéndolos M. Holljen como "registros funcionales de la lengua cotidiana, encargándose la 'traducción técnica' de traducir los textos creados a partir del uso de tales lenguajes" 39 .

En lo que atañe al 'nuevo orden científico-técnico' internacional, hemos comprobado que éste se ha venido afirmando a través de la negación del de épocas anteriores, aunque en la 'creación artístico-literaria y traductológica' no haya ocurrido lo mismo, dado que las revoluciones culturales pueden estallar tumultuosamente pero siempre son acumulables, complementándose con rasgos característicos propios. Finalmente, pese a las dificultades apuntadas anteriormente, recomendamos ser optimistas en cuanto a los beneficios que nos pueda reportar el futuro interdisciplinar de los discursos histórico-lingüístico, artístico-literario, traductológico y científico-técnico, dejando atrás ciertos mensajes agoreros de quienes nos asustan y amenazan con incrédulas catástrofes y banal escepticismo, rechazando de plano las

37 Stephanides, S., «Europe, Globalisation, and the Translatability of Culture», The European English Messenger 12 (2001), 39.

38 Bernárdez, E., El lenguaje como cultura. Una crítica del discurso sobre el lenguaje. Alianza: Madrid 2008, 31-32.

${ }^{39}$ Holljen, M., «Translation studies at a crossroads: Educating translators in minor language communities -a key element in the language planning of modern Norwegian», Translation Journal 1 (1999) (en http:// accurapid.com/journal/07educ.htm). 
enormes ventajas que nos pueda reportar la investigación interdisciplinar en el mundo global en el que nos ha tocado vivir.

Por último, sin dejar de ser realistas, imaginemos, aunque sólo sea por un instante fugaz, que tanto Homero como Virgilio viajaran velozmente en el tiempo, emulando ambos al dios Hermes, y tuviéramos el sumo privilegio de que fueran nuestros insignes cicerones, conduciéndonos hasta las puertas de un 'nuevo e idílico paraiso', donde la intercomunicación entre las ciencias resultara fácil y sin trabas molestas. Probablemente, estaríamos viviendo un sueño utópico, al estilo de Tomás Moro o Aldous Huxley, pero tal vez mereciera la pena experimentar dicho sueño maravilloso, para así lograr contactar con investigadores honrados, y reacios a intrigas palaciegas, cuyo único objetivo fuera investigar en aras del bienestar social de la humanidad, evitándose con ello la propagación de pandemias terribles, guerras cruentas, corrupción generalizada, torres de Babel funestas, envidias y pillajes, desgraciadamente habituales en nuestra crispada sociedad actual, tan irresponsablemente frívola, codiciosa e ignorante. 